\title{
GERENCIAMENTO ÁGIL DE PROJETOS COM SCRUM E KANBAN: DESENVOLVENDO COMPETÊNCIAS ESTRATÉGICAS NA ELABORAÇÃO DE MATERIAL DIDÁTICO DE UM CURSO SUPERIOR EM EAD
}

\author{
ITAPERUNA/RJ MAIO/2018
}

\author{
Joelmir Vinhoza Canazaro - UNIREDENTOR - joelmirvcanazaro@gmail.com \\ Andre Raeli Gomes - UNIREDENTOR - raeli@redentor.edu.br \\ Luiz Gustavo Xavier Borges - UNIREDENTOR - luizgustavo@redentor.edu.br \\ Raphael Ferreira Ramos - UNIREDENTOR - raphaelframos@gmail.com \\ Vinícius de Oliveira Barbosa - UNIREDENTOR - mech.barbosa@gmail.com \\ Jamil Bussade Neto - UNIREDENTOR - jamilbussade@redentor.edu.br
}

Tipo: Relato de Experiência Inovadora (EI)

Categoria: Métodos e Tecnologias

Setor Educacional: EDUCAÇÃO SUPERIOR

\begin{abstract}
RESUMO
Este artigo relata o resultado de uma pesquisa-ação, realizada em uma Instituição de Ensino Superior (IES), no departamento de Educação a Distância (EaD). Fora utilizado como referência a metodologia Scrum e Kanban com apoio da ferramenta online Trello, em um curso superior intitulado Jogos Digitais. A empresa objeto desta atua em Itaperuna/RJ e seu principal serviço é a educação. Estudos indicam que em um cenário de educação a distância, os projetos estão sujeitos a mudanças constantes devido ao grande fluxo de informações. Neste contexto, o departamento de EaD tem um desafio ainda maior do que da implantação de um novo curso, gerenciar tais informações tanto em nível estratégico como operacional, tornar o trabalho visível para os envolvidos e demonstrar indicadores de melhoria competitiva. O presente estudo tem como objetivo principal investigar a celeridade que o método ágil Scrum dá ao processo de desenvolvimento de material didático de um curso superior a distância. Conclui-se que os resultados obtidos sugerem que a comunicação melhorou, diminui o risco e tempo do projeto e aumentou a produtividade da equipe. Com esses resultados alcançados, a instituição tende a se tornar mais competitiva, pois a bemsucedida gestão de informação é ponto primordial para o sucesso de uma empresa de base educacional.
\end{abstract}

Palavras-chave: scrum; kanban; trello; material didático; educação a distância

\section{AGRADECIMENTOS}

\footnotetext{
AGRADECEMOS À EMPRESA OBJETO DE ESTUDO QUE NÃO MEDIU ESFORÇOS EM AJUDAR NA DISPONIBILIDADE DOS DADOS PARA O SUCESSO DESTA PESQUISA.
} 


\section{1 - INTRODUÇÃO}

A Educação a Distância (EaD) vem em uma crescente expansão e efetiva concretização, principalmente com o surgimento de novas tecnologias e pela adoção da internet como ferramenta de estudos. Em contrapeso, a Instituição de Ensino Superior (IES) que deseja atuar na educação a distância enfrenta a necessidade de mudanças de seus serviços educacionais para atender um público cada vez mais exigentes. Outrossim, da preocupação com a estrutura do curso, que vai desde o corpo docente à elaboração de conteúdo, existe também o desafio de gerenciar todas às informações de maneira ágil tanto em nível estratégico como operacional. Dessa forma, o presente artigo científico busca investigar que a implantação do gerenciamento ágil com Scrum e Kanban (Trello), pode ser encarado como benéfica. Já que, a sua correta implementação pode vir reduzir gastos, tempo e conseguinte melhorias na comunicação, aumentando a organização e produtividade da empresa.Quando se fala em Gerenciamento Ágil de Projetos, é muito comum vir à tona a palavra AGILIDADE, que é, numa definição geral, um conjunto recomendado de processos e ferramentas flexíveis de gerenciamento de projetos, direcionadas a projetos complexos que acontecem em ambientes de constante mudanças. Conforme prevê o Scrum Guide (2017), AGILIDADE é uma filosofia que visa orientar atitudes e comportamentos. O referido guia define, ainda, que o Scrum é um framework que contribui com a produtividade e criatividade das pessoas, fazendo com que elas consigam gerenciar complexidade, imprevisibilidade e mudanças por meio da visibilidade, inspeções e adaptações, entregando projetos com o mais alto valor. A seguir, conforme o repositório DEaD do IFCE (Instituto Federal de Educação Profissional e Tecnológica, 2014), existem algumas "tecnologias educacionais" que devem ser utilizadas objetivando a qualidade na elaboração de novos projetos pedagógicos no que tange a apresentar, armazenar, manipular, o conteúdo didático ou informação. A Figura 01 traz os recursos interativos online mais comuns utilizados em ambientes EaD.

Figura 1: Recursos interativos.

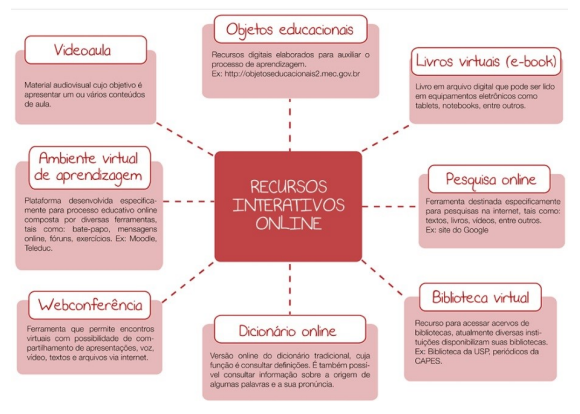

Fonte: DEaD/IFCE (2014) 
A IES objeto de estudo demonstrou grandes preocupações com os recursos interativos online ofertadas ao aluno. Sendo os principais utilizados por ela apresentado brevemente: Livros virtuais (e-book): Livro em arquivo digital chamado "caderno" contendo 16 aulas abordando vários conteúdos de aula; Videoaula: Material audiovisual gravado pelos docentes abordando a respectiva aula do caderno; Biblioteca virtual: Ambiente no qual o aluno acessa acervos de livros da biblioteca virtual Pearson; Ambiente virtual de aprendizagem: Plataforma online, onde os alunos enviam trabalhos, exercícios, mensagem, fóruns, assistem aos vídeos, leem ou fazem o download do caderno. Dentre os quais se destaca o caderno (e-book) que é confeccionado pelo professor conteudista que em muito dos casos é também o professor da disciplina. Tendo por referências autores conceituados adequando ele ao conteúdo da aula, contendo este uma escrita mais próxima ao aluno. Isso se dá pelo fato dos alunos e professores nessa modalidade "não coincidirem em tempo e lugar", se fazendo necessário o uso de tais recursos visando garantir a "comunicação e socialidade". Desse modo, cooperando nessa proximidade e colaborando no desenvolvimento do ensino-aprendizagem mediante as necessidades e expectativas dos alunos.

\section{2 - MATERIAIS E MÉTODOS}

O presente artigo adaptou para a realidade da empresa estudada o Scrum e Kanban utilizando o softwareTrello (2017). Foram utilizados exemplos disponíveis no Trello e o método de Sutherland (2016). De maneira clara e precisa o autor resume qual é a melhor forma de começar um projeto Scrum. Os materiais didáticos utilizados no experimento foram fornecidos pela IES objeto de estudo, situado no município de Itaperuna-RJ. Foram utilizadas informações correspondente aos cadernos (e-book) equivalente ao $1^{\circ}$ período do curso Tecnólogo em Jogos Digitais na modalidade EaD.

\section{1 - METODOLOGIA}

Como caracterização da pesquisa, elegeu-se o presente artigo como natureza apliacada, pois, visa o proveito prático da aplicabilidade de seus resultados na resolução de problemas existentes. A pesquisa quanto aos seus objetivos é descritiva, uma vez que, busca descrever particularidades do objeto de estudo e demonstrar vínculo entre as condições. O referencial teórico utilizado na elaboração do instrumento de pesquisa foi o frameworkScrum e o Kanban (Trello). Para a coleta de dados, utilizou-se como estratégia a pesquisa-ação. Em sua obra, Sutherland (2017, p.184) resume em 11

pontos "sobre a melhor forma de começar um projeto Scrum" ${ }^{13}$ " conforme abaixo: 1. Escolha o Dono do Produto (Product Owner-PO); 2. Escolha uma equipe; 3. Escolha o Scrum Master (Mestre Scrum - Facilitador); 4. Crie e priorize uma lista de Pendências 
do Produto; 5. Aperfeiçoe e faça estimativas para as Pendências do Produto; 6. Planejamento do Sprint; 7. Torne o trabalho visível; 8. Reuniões Diárias ou Scrum Diário; 9. Revisão ou Demonstração do Sprint; 10. Retrospectiva do Sprint; 11. Comece imediatamente o próximo Sprint. Neste projeto executou-se os pontos abordados acima conforme descritos a seguir.

\subsection{1 - Definindo os papéis}

Foram realizadas as divisões dos três papéis que o Scrum prescreve. (SUTHERLAND, 2016). Ademais, Sutherland (2016) defende que a ideia de papéis bem definidos são o princípio de projetos bem-sucedidos. Já que, o Scrum promove a "união das equipes", tornando-as transcendentes, autônomas e interfuncionais. No Quadro 01 são apresentados a equivalência de papéis segundo a configuração proposta, atendendo assim, aos três primeiros tópicos estabelecidos por Sutherland.

Quadro 1: Equivalências de papéis.

\begin{tabular}{|c|c|c|}
\hline Metodologia Scrum & Participantes & Responsabilidade \\
\hline Product Owner (Dono do Produto - PO) & $\begin{array}{c}\text { Coordenador do } \\
\text { Curso de Jogos } \\
\text { Digitais. }\end{array}$ & $\begin{array}{c}\text { Responsável por liderar o es- } \\
\text { forço de desenvolvimento para } \\
\text { criar um produto que gere be- } \\
\text { neficios desejados }\end{array}$ \\
\hline Scrum team (Equipe Scrum) & $\begin{array}{c}\text { Estagiários de } \\
\text { Design Instrucio- } \\
\text { nal, Administra- } \\
\text { dor do Ambiente } \\
\text { Virtual e Peda- } \\
\text { goga. }\end{array}$ & $\begin{array}{c}\text { Responsável por identificar, } \\
\text { estimar e gerenciar as tarefas } \\
\text { Responsável pelo "como" usar } \\
\text { o Scrum de maneira correta }\end{array}$ \\
\hline Scrum Master (Mestre Scrum - Facilitador) & Gerente EaD. & $\begin{array}{c}\text { Responsável por identificar, } \\
\text { estimar e gerenciar as tarefas }\end{array}$ \\
\hline
\end{tabular}

Fonte: Vasconcelos (2016)

\subsection{2 - Criando e priorizando a lista de pendências}

A montagem do Dashboard Scrum também chamado Quadro Scrum se deu pelo softwareTrello. O Trello faz uso da ideologia do Kanban que visa por meio de controle visual acompanhar o trabalho à medida que ele flui através das várias etapas do fluxo de valor. O quadro é composto por listas e cartões conhecido por post-its. Nele fora criado a lista de pendências, no Scrum chamada de Backlog do Produto (Product Backlog). Cada cartão corresponde a um caderno que compõem o $1^{\circ}$ período do curso Tecnólogo em Jogos Digitais conforme descrito: Álgebra Linear; Algoritmos de Programação; Criação e Edição de Imagens; Introdução a Jogos Digitais; Matemática para Computação; Metodologia Científica; Organização de Computadores; Português Instrumental; Projeto Integrador I. 
A lista fora aperfeiçoada pela equipe da seguinte maneira: Organizando os cadernos em ordem alfabética; O time estimou o esforço produzido para realização das tarefas de cada caderno; Utilizou a extensão Scrum for Trello no navegador Google Chrome para estimar o esforço produzido; Fora classificado cada caderno relativamente através da sequência de Fibonacci ?,0,0.5,1,2,3,5,8,13,21. O menor valor exige menos esforço, bem como o maior exige mais. O valor "?" é atribuído quando há dúvida da equipe em relação ao Sprint. O valor estimado aparece à esquerda do nome do caderno e o valor alcançado à direita. O time responsável pela editoração do caderno aprimorou junto ao Dono do Produto e ao Mestre Scrum cada cartão (caderno) através de um Checklist. O checklist contém informações importantes para toda a equipe. A medida que forem executadas o membro tem por responsabilidade marcar o checklist, logo, todos os envolvidos no caderno serão notificados. Existe possibilidades diversas como por exemplo, anexar arquivos, etiquetas que servem de lembretes, adicionar novos membros e excluir outros, dentre outros. No entanto, a equipe escolheu por hora algumas informações que julgou serem importantes.

\subsection{4 - Planejando Sprint}

Primeira reunião para planejar os ciclos chamado Sprint [corrida de velocidade de curta distância] que envolveu a equipe, o Mestre Scrum e o Dono do Produto. No Sprint, a duração de tempo é menor que um mês. Ao final da reunião a equipe decidiu a quantidade de trabalho que acredita ser capaz de realizar. $O$ acordado fora 21 dias úteis para execução do Sprint. Tendo por início o dia 05 de dezembro do ano letivo de 2017. Fazia parte do Sprint entregar todos os cadernos editorados para futura publicação.

\subsection{5 - Tornando o trabalho visível}

Fora utilizado o Quadro Scrum com quatro colunas: A fazer (do), fazendo (doing), feito (done) e impedimentos (Obstacles). A seguir são descritos brevemente o que representa cada coluna no Scrum: A fazer (Do): Coluna destinada a receber os entregáveis priorizados; Fazendo (Doing): Coluna destinada a receber os entregáveis que estão sendo executados; Feito (Done): Coluna destinada a receber os entregáveis finalizados, ou seja, prontos; Impedimentos (Obstacles - Blocked): Coluna destinado aos entregáveis que sofreram algum impedimento durante o processo. Outra forma de demonstrar o que fora feito para equipe se dá pelo Gráfico Burnup e o Gráfico Burndown que mostra três retas, sendo: pontos completos na cor vermelho, pontos restantes na cor azul e ideal na cor amarelo que demostra o valor ideal em pontos. A Figura ilustra o Gráfico Burndown.

Figura 2: Gráfico Burndown. 


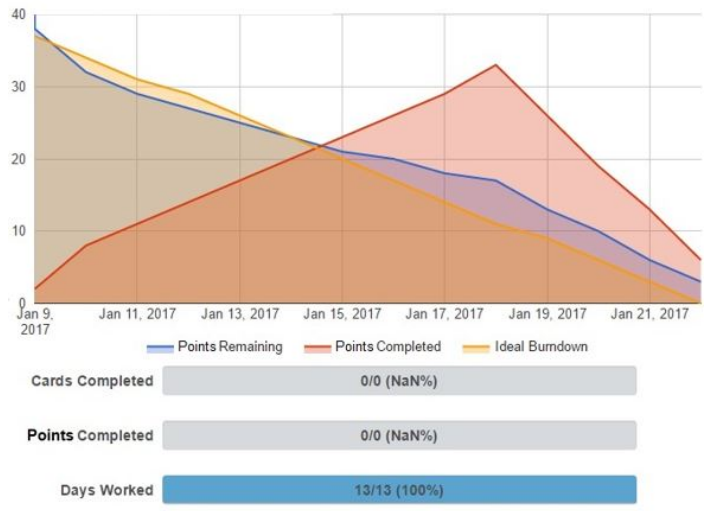

Fonte: Trello (2017)

A ferramenta Trello notifica em tempo real todas às mudanças que ocorrem no projeto. Por quem, quando e a que horas fora a mudança. Desse modo, qualquer membro da equipe recebe o alerta no e-mail e smartphone, conseguindo assim interpretar o que está acontecendo.

\subsection{6 - Reuniões Diárias}

O Mestre Scrum se reúne com a equipe todos os dias. Não mais que 15 minutos onde respondem três perguntas: $O$ que você fez ontem para ajudar a equipe a concluir 0 Sprint?; O que você vai fazer hoje para ajudar a equipe a concluir o Sprint? ; Existe algum obstáculo impedindo você ou a equipe de alcançar o objetivo do Sprint?

Nessa reunião fora percebido os possíveis gargalos e conseguinte as medidas a serem tomadas a fim de trata-los e soluciona-los.

\subsection{7 - Revisão ou Demonstração do Sprint}

Reunião na qual a equipe demonstrou o que conseguiu colocar na coluna feito. O que está concluído sem qualquer retrabalho.

\subsection{8 - Retrospectiva do Sprint}

Reunião na qual a equipe e o Mestre Scrum acordaram o que fora proveitoso e descartável no Sprint atual para aprimorar o processo que será implementado no próximo Sprint.

\subsection{9 - Começando próximo Sprint}


O próximo Sprint se iniciará levando em consideração a experiência adquirida pela equipe em relação aos impedimentos e os aprimoramentos no processo.

\section{3 - RESULTADOS E DISCUSSÕES}

De acordo com o que foi exposto no capítulo de introdução e metodologia segue a demonstração do desenvolvimento da implantação do Scrum e Kanban a empresa estudada. Na Figura 3 são apresentados o atual cenário em relação aos cadernos.

Figura 3: Cenário atual.

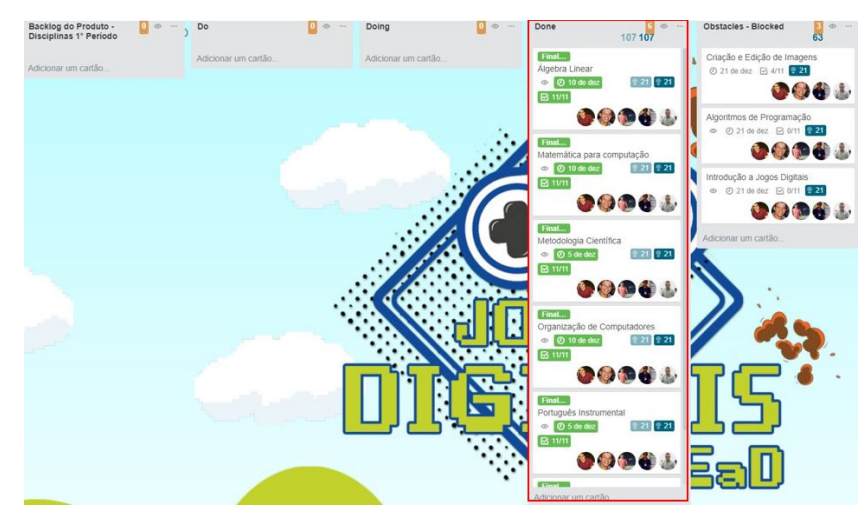

Fonte: Trello (2017)

Nela, se pode visualizar que a coluna "feito" se encontra quase por completa. A Figura 4 abaixo demonstra o checklist completo de um caderno, onde toda a equipe pode ver 0 esforço estimado fora alcançado.

Figura 4: Checklist completo.

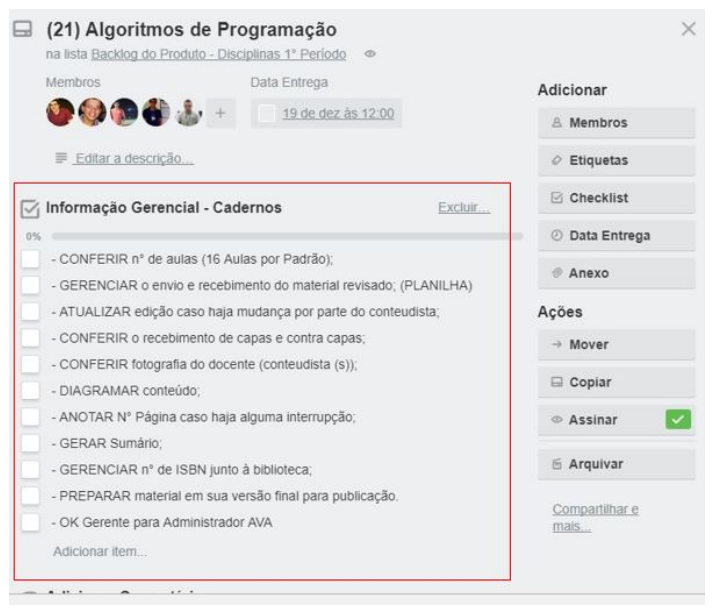

Fonte: Trello (2017) 
A partir da análise do gráfico, representado na figura a seguir, foi possível visualizar quais foram os resultados obtidos utilizando o método exposto por Sutherland.

Figura 5: Gráfico Burndown em relação ao esforço estimado pela equipe.

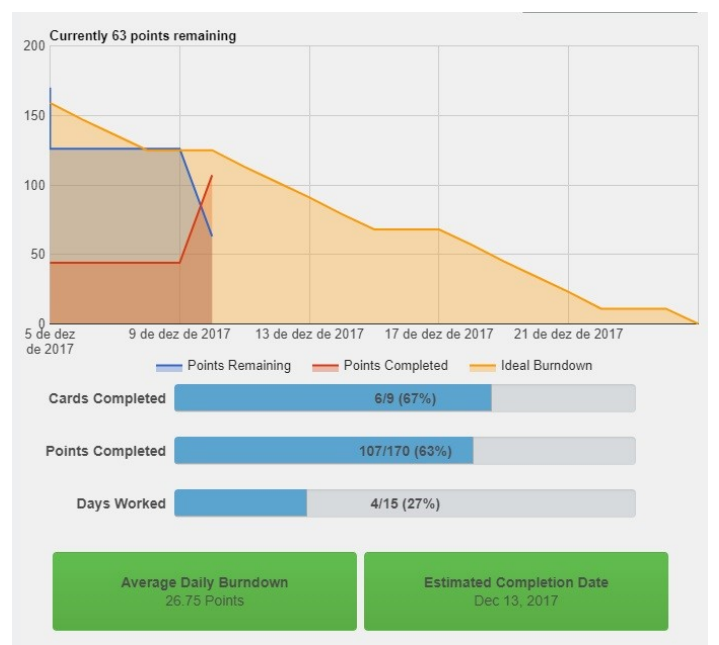

Fonte: Trello (2017)

Percebe-se que de 9 cartões 6 foram concluídos, o que corresponde $67 \%$ do projeto. Mais adiante, é visto que dos 170 pontos no total estimados pela equipe no início do projeto foram atingidos 107 até o dia 14 de dezembro de 2017 , o que equivale $63 \%$ do que fora planejado. Ademais, dos 15 dias de trabalho que foram planejados, atingiu-se os respectivos valores mencionados em 4 dias. Restam 63 pontos para que a equipe atinja o objetivo proposto de 21 dias. $O$ total de 170 pontos a ser atingido bem como 0 exato 107 pontos em que a equipe se encontra é melhor ilustrado conforme o Gráfico Burnup abaixo.

Figura 6: Gráfico Burnup do projeto.

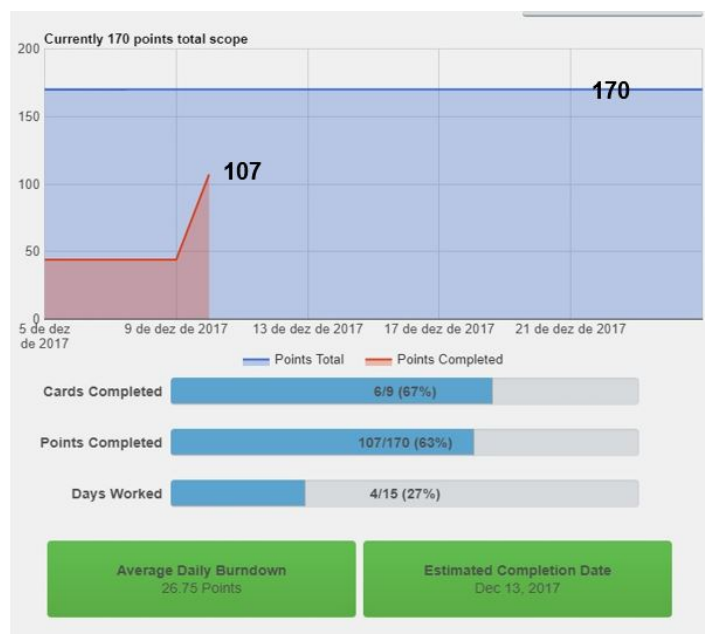


Fonte: Trello (2017)

\section{4 - CONSIDERAÇÕES FINAIS}

Após a análise completa dos resultados foi possível concluir que é viável utilizar Scrum e Kanban na elaboração de material didático de um curso superior em EaD, pois tal implantação apresenta uma forma visual fácil de interpretar. Além disso, estes sistemas são adaptativos mesmo quando da mudança de algum requisito. Os valores encontrados para os cadernos, são satisfatórios para aplicação em projetos complexos de educação a distância. Logicamente, cabe dizer que mesmo sendo fácil de entender, a mudança no jeito pelo o qual o trabalho é encarado no Scrum, causa restrição por parte de alguns. Outro ponto relevante, é a exposição nas tarefas e a transparência com o qual a equipe tem que Ihe dar gerando assim alguns desafios em sua implantação.

\section{REFERÊNCIAS BIBLIOGRÁFICAS}

CARVALHO, BV de; MELLO, Carlos Henrique Pereira. Aplicação do método ágil scrum no desenvolvimento de produtos de software em uma pequena empresa de base tecnológica. Gestão \& Produção, v. 19, n. 3, p. 557-573, 2012.

CEARÁ. Cristiane Borges. Rede Federal de Educação Profissional e Tecnológica. Os recursos e ferramentas utilizadas em EaD. Ceará: Instituto Federal Ceará, 2014.

HERMONT, Arabie Bezri.; ASSUMPÇÃO, Solange Bonomo. Educação a distância: como revisar os materiais didáticos. Scripta, Belo Horizonte, v. 14, n. 26, p. 179-194, 1ํosem. 2010.

KNIBERG, H. Kanban e Scrum - obtendo o melhor de ambos. InfoQ, 2009.

Koerich MS, Backes DS, Sousa FGM, Erdmann AL, Albuquerque GL. Pesquisa-ação: ferramenta metodológica para a pesquisa qualitativa. Ver. Eletr. Enf. [Internet]. 2009; 11(3):717-23.

MANIFESTO ÁGIL. 2001. Disponível em: . Acesso em: 10 ago. 2017.

ROESLER, Jucimara; GERENCIAMENTO, Categoria. A gestão da educação superior on-line. Tubarão: Editora Unisul, 2008. 
e da produção de materiais didáticos impressos e on-line. Tubarão: Editora Unisul, 2005.

SCHWABER, Ken; SUTHERLAND, Jeff. Guia do Scrum ${ }^{\mathrm{TM}}$ : Um guia definitivo para o Scrum: As regras do jogo. 2017.

SUTHERLAND, Jeff. Scrum: a arte de fazer o dobro do trabalho na metade do tempo. Leya, 2016.

THIOLLENT, M. Metodologia da pesquisa-ação. 14. ed. São Paulo: Cortez, 2005.

TRELLO. Trello. 2017. Disponível em: . Acesso em: 10 ago. 2017.

VASCONCELOS, Yumara Lúcia. Metodologia Scrum e a gestão de atividades didático-pedagógicas realizadas em colaboração. 2016. 